\title{
Genetic Diversity Analysis of Indian Mustard (Brassica spp.) Germplasm Lines using SSR Molecular Markers
}

\author{
Ravi Baghel ${ }^{1}$, A. K. Sharma ${ }^{1}$, Sushma Tiwari ${ }^{1}$, M. K. Tripathi ${ }^{1 *}$ and Niraj Tripathi ${ }^{2}$ \\ ${ }^{1}$ Department of Plant Molecular Biology and Biotechnology, College of Agriculture, \\ Rajmata Vijayaraje Scindia Agricultural University, Gwalior-474002, India \\ ${ }^{2}$ Directorate of Research Services, Jawaharlal Nehru Agricultural University, \\ Jabalpur-482004, India \\ *Corresponding author
}

\section{A B S T R A C T}

\begin{tabular}{|l} 
K e y w o r d s \\
Indian mustard, \\
$\begin{array}{l}\text { Cluster analysis, } \\
\text { Diversity analysis, } \\
\text { SSR marker }\end{array}$ \\
\hline Article Info \\
\hline $\begin{array}{l}\text { Accepted: } \\
\text { 04 November } 2020 \\
\text { Available Online: } \\
\text { 10 December } 2020\end{array}$
\end{tabular}

\section{Introduction}

Oilseed Brassica occupies an imperative spot in the agriculture due to useful oil content. In most of the provinces of the world, its cultivation has risen tremendously during the last periods and, by now; it is the third largest contributor of the world supply of vegetable oil. Rapeseed is one of the most significant oil and protein rich annual crops in the world. Seed provides oil both for industrial and cooking purposes. The oils extracted from mustard contain high protein (37\%) and feed concentration which is highly palatable to livestock. So, it is urgent to analyse the genetic diversity and its response for the selection of short duration mustard genotypes for increasing our cropping intensity.

Presence of diversity at marker loci is presently the most feasible strategy for characterizing diversity among mustard germplasm lines. Molecular markers offer the best estimate of genetic diversity, since these are independent from the difficult effects of environmental factors. In mustard, various 
marker systems have been applied for detecting the genetic diversity. There are increasing number of reports where molecular markers like Restriction fragment length polymorphism (RFLP) (Diers and Osborn, 1994; Hallden et al., 1994), random amplified polymorphic DNAs, (RAPDs) (Ghosh et al., 2009; Khan et al., 2011, Tripathi et al., 2012), amplified fragment length polymorphism (AFLP) (Sun et al., 2001; Zhao et al., 2005, Tripathi et al., 2011) and microsatellites or simple sequence repeats (SSRs) (Abbas et al., 2009; Wang et al., 2009; Tiwari et al., 2019) have been used to study genome organization, varietal differences and diversity analysis in Brassicas. Among all molecular markers, Simple Sequence Repeats (SSRs) or microsatellites have been distinguished as constructive molecular markers in marker assisted selection (MAS), for the analysis of genetic diversity (Kachare et al., 2019), population analysis (Tiwari et al., 2019) and other purposes in various species (Tripathi and Khare, 2016; Mishra et al., 2020; Pramanik et al., 2019; Shyam et al., 2020; Upadhayay et al., 2020). Several hundred SSR markers have been developed for Brassica genotypes (Kumar et al., 2015). But, no systematic work on molecular diversity analysis among the germplasm lines selected for the current study has been performed. So, the present investigation was undertaken to study the genetic diversity among germplasm lines of mustard at molecular level to see inherent relationship between and among the germplasm lines for incorporation in mustard breeding programme.

\section{Materials and Methods}

Experimental material consists of forty-eight Indian mustard genotypes (Table 1) obtained from the Zonal Agricultural Research Station, Morena, Rajmata Vijayaraje Scindia Krishi Vishwa Vidyalay, Gwalior, Madhya Pradesh (AICRP on Rapeseed and Mustard).The present investigation was conducted at the Department of Plant Molecular Biology and Biotechnology to characterize mustard germplasm lines at molecular level with the use of SSR markers. DNA was isolated from actively growing fresh leaves of 20 to 25 days old seedlings using Cetyl Trimethyl Ammonium Bromide (CTAB) method. DNA quality was confirmed by electrophoresis on $0.8 \%$ agarose gel and quantified using a spectrophotometer. Initially a total of 20 SSR primers were tested and only polymorphic markers were used for further analysis. For polymerase chain reaction initial denaturation at $94^{\circ} \mathrm{C}$ for $3 \mathrm{~min}$; denaturation at $94^{\circ} \mathrm{C}$ for 1 min; annealing at $35^{\circ} \mathrm{C}$ for $45 \mathrm{sec}$; elongation or extension at $72^{\circ} \mathrm{C}$ for $45 \mathrm{sec}$.; Cycle to step 2 for 40 more time; final extension at $72^{\circ} \mathrm{C}$ for $5 \mathrm{~min}$ were performed. The amplified products were separated electrophoretically on $2.5 \%$ agarose gel containing ethidium bromide. Molecular weight marker of $100 \mathrm{bp}$ DNA ladder was electrophoresed alongside with the PCR products. DNA bands were observed on UV-transilluminator in the dark chamber of the Image Documentation System. Bands were scored according to their sizes. The scores obtained using all primers in the SSR analysis were pooled to create a single data matrix. This was used to construct a UPGMA dendrogram.

\section{Results and Discussion}

Genetic diversity investigation is the first and leading footstep in any crop advancement agenda. Usually, to have a reliable estimate of genetic relationship and genetic diversity, a large number of polymorphic markers are applied. DNA analysis with markers is a very effective tool for analyzing genetic diversity. Out of all types of molecular markers, SSR markers have been extensively used in many crops as genetic markers for the assessment of genetic diversity and found to be successful in the characterization of individual with their 
pedigree. These markers are dominant and can detect variation in non-coding regions of the genome.

The randomly selected 20 SSR primers were shortlisted based on banding patterns by using DNA samples of two mustard germplasm lines. Out of them, the best eight amplified SSR markers were picked for an advance work. Among these 8 markers, only one marker showed monomorphic bands while 7 markers confirmed polymorphic bands. In total $50 \%$ polymorphism was observed. Mishra et al., (2011) and Prajapat et al., (2014) also found analogous results. They documented $\quad 72 \% \quad$ polymorphism. Comparative genomics in Brassica have demonstrated that microsatellite characteristics in related species are highly similar (Shi et al., 2014). Intra-generic transferability of SSRs had been reported earlier in many studies, i.e. SSRs from Pennisetum glaucum to $P$. Purpureum, Brassica species to $B$. tournefortii, $B$. Fruticulosa and B. Spinescens (Singh et al., 2012). Transferability of SSR markers between A- and C- genomes of Brassica species had also been assessed by Saal et al., (2001), which corresponded to the already established evolutionary relationship. In a genetic diversity analysis with Indian mustard genotypes and SSR markers, Parida et al., (2010) reported only 2 alleles per locus, where the fragment size varied from 100 to $2000 \mathrm{bp}$.

Table.1 List of germplasm lines used in present study

\begin{tabular}{|c|c|c|c|c|c|}
\hline S. No. & Germplasm lines & Collection site & S. No. & Germplasm lines & Collection site \\
\hline 1. & MRNJ-92 & BTE & 25. & MRNJ-123 & BTE \\
\hline 2. & MRNJ-93 & BTE & 26. & MRNJ-125 & BTE \\
\hline 3. & MRNJ-95 & BTE & 27. & MRNJ-126 & BTE \\
\hline 4. & MRNJ-97 & BTE & 28. & MRNJ-127 & BTE \\
\hline 5. & MRNJ-98 & BTE & 29. & MRNJ-129 & BTE \\
\hline 6. & MRNJ-99 & BTE & 30. & MRNJ-130 & BTE \\
\hline 7. & MRNJ-100 & BTE & 31. & MRNJ-131 & BTE \\
\hline 8. & MRNJ-101 & BTE & 32. & MRNJ-132 & BTE \\
\hline 9. & MRNJ-103 & BTE & 33. & MRNJ-133 & BTE \\
\hline 10. & MRNJ-104 & BTE & 34. & MRNJ-135 & BTE \\
\hline 11. & MRNJ-107 & BTE & 35. & MRNJ-137 & BTE \\
\hline 12. & MRNJ-108 & BTE & 36. & MRNJ-139 & MRA \\
\hline 13. & MRNJ-109 & BTE & 37. & MRNJ-140 & MRA \\
\hline 14. & MRNJ-110 & BTE & 38. & MRNJ-142 & MRA \\
\hline 15. & MRNJ-111 & BTE & 39. & MRNJ-143 & GCT \\
\hline 16. & MRNJ-112 & BTE & 40. & MRNJ-145 & GCT \\
\hline 17. & MRNJ-113 & BTE & 41. & RB-50 & BWL \\
\hline 18. & MRNJ-114 & BTE & 42. & IDM-25 & MRA \\
\hline 19. & MRNJ-115 & BTE & 43. & CS-54 & KUN \\
\hline 20. & MRNJ-116 & BTE & 44. & RVM-1 & GWL \\
\hline 21. & MRNJ-119 & BTE & 45. & NRCDR-2 & BTE \\
\hline 22. & MRNJ-120 & BTE & 46. & RVM-2 & GWL \\
\hline 23. & MRNJ-121 & BTE & 47. & IDM-16 & MRA \\
\hline 24. & MRNJ-122 & BTE & 48. & ROHINI & $\mathrm{CNB}$ \\
\hline
\end{tabular}

BTE - Bharartpur, MRA - Morena, GCT - Ghazipur, BWL - Bawal, KUN - Karnal, CNB - Kanpur, GWL - Gwalior. 
Table.2 Polymorphism revealed by SSR markers assays of mustard germplasm lines

\begin{tabular}{|l|c|c|c|c|c|}
\hline SSR Marker & $\begin{array}{c}\text { Major Allele } \\
\text { Frequency }\end{array}$ & $\begin{array}{c}\text { Genotype } \\
\text { Number }\end{array}$ & Allele Number & Gene Diversity & PIC value \\
\hline BRMS- 240 & 0.5000 & 4.0000 & 4.0000 & 0.5877 & 0.5047 \\
\hline BRMS- 324 & 0.4583 & 6.0000 & 5.0000 & 0.6727 & 0.6164 \\
\hline SR- 7223 & 0.5208 & 3.0000 & 3.0000 & 0.5182 & 0.4038 \\
\hline SR- 9222 & 0.3958 & 5.0000 & 5.0000 & 0.7196 & 0.6723 \\
\hline SR 94102 & 0.3958 & 5.0000 & 4.0000 & 0.6968 & 0.6395 \\
\hline OI 10-CO 5 & 0.3750 & 5.0000 & 5.0000 & 0.7300 & 0.6851 \\
\hline SSR Na10-D09 & 0.3750 & 5.0000 & 5.0000 & 0.7222 & 0.6740 \\
\hline Mean & $\mathbf{0 . 4 3 1 5}$ & $\mathbf{4 . 7 1 4 3}$ & $\mathbf{4 . 4 2 8 6}$ & $\mathbf{0 . 6 6 3 9}$ & $\mathbf{0 . 5 9 9 4}$ \\
\hline
\end{tabular}

Fig.1 The diagrammatic representation of clusters based on SSR data prepared using power marker 3.25 software

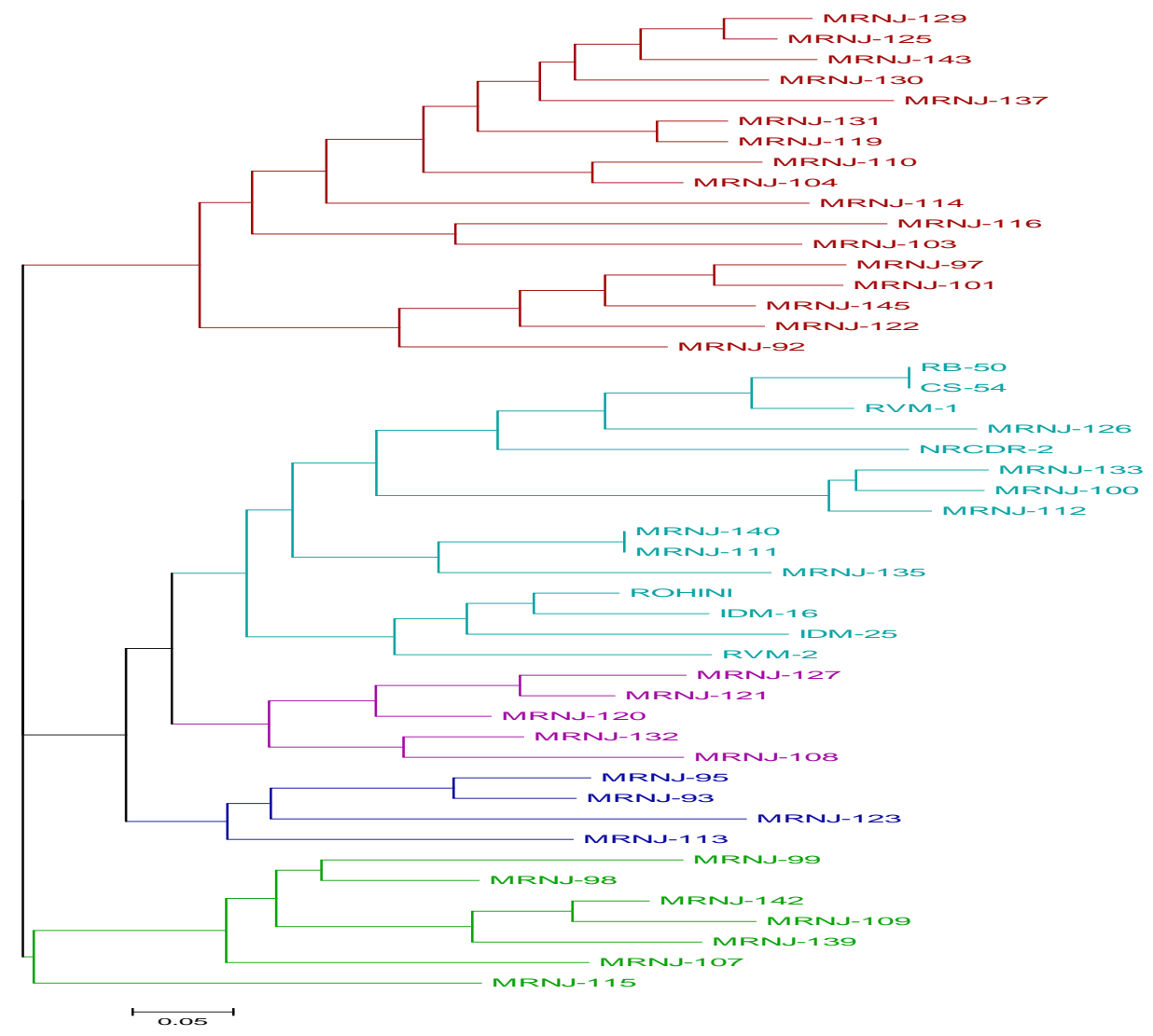

The summary statistics extracted from Power Marker was scrutinized for allele number, major allele frequency, genotype number, gene diversity, heterozygosity and Polymorphism Information Content (PIC). Major Allele Frequency ranged from 0.3750 to 0.52 with a mean value of 0.43 . Heterozygosity ranged between 0 and 20. The mean heterozygosity was 0.03 . Polymorphism information content (PIC) was estimated for each of the 7 SSR markers. Higher value of PIC indicated higher polymorphism of the 
SSR markers and assists to select the best SSR markers in phylogenic analysis. Highest PIC value (0.6851) was documented for SSR marker OI10-CO 5 which has 8 alleles among the 48 genotypes. Molecular markers SSR Na10-D09, SR- 9222 and BRMS-324 also had higher PIC scores and high number of alleles (Table 2). The lowest PIC value was attained with SR-7223 (0.4038) marker. Mean PIC value was 0.59 , representing high diverse nature of marker which can be employed for further characterization. Pandey et al., (2012) found that only 15.7 percent of markers gave PIC values greater than 0.5 . They found that allelic values ranging from 5 to 11 . Thus, the number of alleles directly influenced the PIC value (Tantasawat et al., 2011; Tiwari et al., 2019). The PIC ranged from 0.75 to 0.993 and genetic similarity varied between 0.478 and 1.000 .

Based on electrophoretic banding pattern of SSR primers, pair-wise genetic similarity among 48 genotypes was estimated and a dendogram was generated (Fig. 1). Cluster analysis revealed that accessions of Brassica juncea L. under study, fell into major group and sub groups. The cluster analysis disclosed two main clusters with highest $58 \%$ similarity percentage (Gohel et al., 2014). Kumar et al., (2011) also estimated Jaccard's similarity coefficients and constructed dendogram by using UPGMA revealed the presence and extent of genetic similarities among mutants ranged from 0.54 to 0.91 . In present investigation, major group contained 48 genotypes that divided into three main groups, first main group ' $\mathrm{I}$ ' included 17 genotypes, second main group 'II' hold 24 genotypes and third main group 'III' possessed 7 genotypes. According to Jaccard's similarity coefficient, highest similarity was found between MRNJ119 and MRNJ-131 in sub group 'A'. Both genotypes were grouped together. The uppermost genetic diversity was observed in main group 'A' between MRNJ-92 and
MRNJ-129. Both of the germplasm lines were grouped distantly. In subgroup ' $B$ ' maximum similarity was recorded between RB- 50 and CS - 54, and highest genetic diversity was observed between RVM -1 and MRNJ-113. At last in sub group ' $C$ ' utmost similarity and highest genetic diversity was observed between germplasm lines MRNJ-142 and MRNJ-109 and MRNJ-99 and MRNJ115 correspondingly. Some genotypes are falling in same group existing possibility of many traits to be similar whereas the genotypes falling extremely apart from whole of the cluster shows the possibility of discovering new traits in them which could be further assisted in conventional and /or molecular breeding programmes.

\section{References}

Abbas, S.J., Ullah, F., Marwat, K.B., Khan, I.A. and Munir, I. 2009. Molecular analysis of genetic diversity in Brassica species. Pak. J. Bot. 41(1): 167-176.

Diers, B.W. and Osborn, T.C. 1994. Genetic diversity of oilseed Brassica napus germplasm based on Restriction Fragment Length Polymorphisms. Theor. Appl. Genet. 88:662-668.

Ghosh, K.K., Haque, M.E., Parvin, M.S., Akhter, F. and Rahim, M.M. 2000. Genetic diversity analysis in Brassica varieties through RAPD markers. Bangladesh J. Agril. Res. 34(3): 493503.

Gohel, K. and Mehta, D.R. 2014. Assessment of genetic diversity among mustard (Brassica juncea (L.) Czern\&Coss) genotypes using PCR based DNA markers. International Journal of Applied And Pure Science and Agriculture (IJAPSA) Volume 01, Issue 01.

Hallden, C., Nilsson, N.O., Rading, I.M. and Sall, T. 1994. Evaluation of RFLP and 
RAPD markers in a comparison of Brassica napus breeding lines. Theor. Appl. Genet. 88:123-128.

Kachare, S., Tiwari, S., Tripathi, N. and Thakur, V.V. 2019. Assessment of genetic diversity of soybean (Glycine $\max$ (L.) Merr.) genotypes using qualitative traits and microsatellite makers. Agricultural Research x: y-z. DOI: 10.1007/s40003-019-00412-y

Khan, W.M., Munir, I., Farhatullah, Arif, M., Iqbal, A., Ali, I., Ahmad, D., Ahmad, M., Mian, A., Bakht, J., Inamullah, and Swati, Z.A. 2011. Assessment of genetic diversity of Brassica juncea germplasm using Randomly Amplified Polymorphic DNA (RAPD) markers. Afr. J. Biotechnol. 10:3654-3658.

Kumar, H., Anubha, Vishwakarma, M. and Lal, J. 2011. Morphological and molecular characterization of Brassica napus sp yellow sarson mutants. J. Oilseed Brassica., 2(1): 1-6.

Mishra, M.K., Suresh, N., Bhat, A.M., Suryaprakash, N., Kumar, S.S., Kumar, A. and Jayarama. 2011. Genetic Molecular Analysis Of Coffea arabica Hybrids Using Srap Markers. Revista De Biologíatropical., 59, 607-617.

Mishra, N., Tripathi, M.K., Tiwari, S., Tripathi, N., Trivedi, H.K. 2020 Morphological and molecular screening of soybean genotypes against yellow mosaic virus disease. Legume Research DOI:10.18805/LR4240 .

Pandey, M.K., Gautami, B., Jayakumar, T., Sriswathi, M., Upadhyaya, H.D., Gowda, M.V.C., Radhakrishnan, T., Bertioli, D., Knapp, S.J., Cook R.D., and Varshney, R.K. 2012. Highly informative genic and genomic SSR markers to facilitate molecular breeding in cultivated groundnut (Arachis hypogaea). ICRISAT Open
Access Repository, 131, 139-147.

Parida, S.K., Yadava, D.K. and Mohapatra, T. 2010. Microsatellites in Brassica unigenes: relative abundance, marker design, and use in comparative physical mapping and genome analysis. Genetic diversity assessment in Indian mustard (Brassica juncea L) for Alternaria blight tolerance using SSR markers. 53: 55-67

Prajapat, P., Sasidharan, N., Kumar, M. and Prajapat, V. 2014. Molecular Characterization And Genetic Diversity Analysis In Four Brassica Species Using Microsatellite Markers. The Bioscan., 9(4): 1521-1527, 2014.

Pramanik, A. Tiwari, S., Tomar, R.S., Tripathi, M.K. and Singh, A.K. 2019. Molecular characterization of groundnut (Arachis hypogaea L.) germplasm lines and varietal set for yield and yield attributing traits. Indian J. Genet., 79(1): 56-65.DOI: https://doi.org/10.31742/IJGPB.79.1.8

Saal, B., Plieske, J., Hu, J., Quiros, C.F. and Struss, D. 2001. Microsatellite markers for genome analysis in Brassica. II. Assignment of rapeseed microsatellites to the $\mathrm{A}$ and $\mathrm{C}$ genomes and genetic mapping in Brassica oleracea L. Theor Appl Genet. 102:695-99

Shi, J., Huang, S., Zhan, J., Yu, J., Wang, X., Hua, W., Liu, S., Liu, G. and Wang, H. 2014. Genome wide microsatellite characterization and marker development in the sequenced Brassica crop species. DNA Res. 21:53-68.

Shyam, C., Tripathi, M.K., Tiwari, S., Tripathi N. and Ahuja, A. 2020. Molecular characterization and identification of Brassica genotype(s) for low and high erucic acid content using SSR markers. Global J. Biosci. Biotechnol. 9(2) 2020: 56 - 66. 
Singh, B.K., Thakur, A.K. and Rai, P.K. 2012. Genetic diversity and relationships in wild species of Brassica and allied genera as revealed by cross-transferable genomic STMS marker assays. Aust J Crop Sci. 6(5):815-21.

Sun, D.L., Zhao, Q.C., Song, W.Q., Chen, R.Y. 2001. Relationships analysis of Chinese cabbage species by AFLP. Acta Horticulture Sinica 28:331-335.

Tantasawat, P., Trongchuen, J., Prajongjai, T., Jenweerawat S., and Chaowiset, W. 2011. SSR analysis of soybean (Glycine max (L.) Merr.) genetic relationship and variety identification in Thailand. Aus. J. Crop Sci, 5, 283 290.

Tiwari, S., Tripathi, N., Tsuji, K. and Tantwai, K. 2019. Genetic diversity and population structure of Indian soybean (Glycine max (L.) Merr.) as revealed by microsatellite markers. Physiol. Mol. Biol. Plants 25: $953-$ 964.

Tripathi, N. and Khare, D. 2016. Molecular approaches for genetic improvement of seed quality and characterization of genetic diversity in soybean: a critical review. Biotechnol. Lett. 38: 16451654.

Tripathi, N., Saini, N., Kumar, S and Tiwari, S. 2012. Assessment of Genetic Diversity among Withania somnifera Collected from Central India using RAPD and ISSR Analysis. J. Med.
Arom Plant Sci. Biotechnol 6 (1): 133 139

Tripathi, N., Saini, N. and Tiwari, S. 201). Assessment of genetic diversity among Aloe vera accessions using amplified fragment length polymorphism. Int. J. Med Arom Plants 1(2):115-121.

Upadhyay, S., Singh, A. K., Tripathi, M.K., Tiwari S. and Tripathi, N. (2020) Validation of simple sequence repeats markers for charcoal rot and Rhizoctonia root rot resistance in soybean genotypes. Int. J. Adv. Biotechnol. Res., 10 (2): 137-144

Wang, J., Kaur, S, Cogan, N.O.I., Dobrowolski, M.P., Salisbury, P.A., Burton, W.A., Baillie, R., Hand, M., Hopkins, C., Forster, J.W., Smith, K.F. and Spangenberg, G. 2009. Assessment of genetic diversity in Australian canola (Brassica napus L.) cultivars using SSR markers. Crop Pasture Sci. 60: 1193-1201.

Yildirim, E., Yildirim, N., Ercisli, S., Agar, G. and Karlidag, H. 2010. Genetic relationships among turnip (Brassica rapa var. rapa) genotypes. Genet. Mol. Res. 9:987-993.

Zhao, J.J., Wang, X.W., Deng, B., Lou, P., Wu, L., Sun, R.F., Xu, Z.Y., Vromans, J., Koornneef, M. and Bonnema, G. 2005. Genetic relationships within Brassica rapa as inferred from AFLP fingerprints. Theor. Appl. Genet. 110: $1301-1314$.

\section{How to cite this article:}

Ravi Baghel, A. K. Sharma, M. K. Tripathi and Niraj Tripathi. 2020. Genetic Diversity Analysis of Indian Mustard (Brassica spp.) Germplasm Lines using SSR Molecular Markers. Int.J.Curr.Microbiol.App.Sci. 9(12): 137-143. doi: https://doi.org/10.20546/ijcmas.2020.912.018 